Louisiana State University

LSU Digital Commons

Faculty Publications

Department of Biological Sciences

$12-1-2004$

\title{
Dominant-negative CREB inhibits heparanase functionality and melanoma cell invasion
}

\author{
Rebecca Aucoin \\ School of Veterinary Medicine \\ Jane Reiland \\ School of Veterinary Medicine \\ Madhuchhanda Roy \\ School of Veterinary Medicine \\ Dario Marchetti \\ School of Veterinary Medicine
}

Follow this and additional works at: https://digitalcommons.Isu.edu/biosci_pubs

\section{Recommended Citation}

Aucoin, R., Reiland, J., Roy, M., \& Marchetti, D. (2004). Dominant-negative CREB inhibits heparanase functionality and melanoma cell invasion. Journal of Cellular Biochemistry, 93 (2), 215-223.

https://doi.org/10.1002/jcb.20231

This Article is brought to you for free and open access by the Department of Biological Sciences at LSU Digital Commons. It has been accepted for inclusion in Faculty Publications by an authorized administrator of LSU Digital Commons. For more information, please contact ir@lsu.edu. 


\title{
FAST TRACK
}

\section{Dominant-Negative CREB Inhibits Heparanase Functionality and Melanoma Cell Invasion}

\author{
Rebecca Aucoin, Jane Reiland, Madhuchhanda Roy, and Dario Marchetti* \\ Department of Comparative Biomedical Sciences, School of Veterinary Medicine, \\ Louisiana State University-Baton Rouge, Baton Rouge, Louisiana 70803
}

\begin{abstract}
Heparanase (HPSE-1) is an endo- $\beta$-D-glucuronidase involved in the degradation of cell-surface/ extracellular matrix heparan sulfate (HS) in normal and neoplastic tissues. HPSE-1 represents the first example of purification and cloning of a mammalian HS-degradative enzyme. Elevated HPSE-1 levels are known to be associated with metastatic cancers, directly implicating HPSE-1 in metastatic events. The purpose of this study was to determine the role of cAMP response element-binding protein (CREB) in modulating HPSE-1-mediated effects on human melanoma cell invasion. Highly invasive, brain-metastatic melanoma cells (70W) were transfected with the dominant-negative CREB (KCREB) and subsequently analyzed for changes in their HPSE-1 content, functionality, and cell invasive properties. KCREB-transfected cells showed a decrease in HPSE-1 mRNA expression and activity. This correlated with a significantly decreased invasion of these cells through Matrigel ${ }^{T M}$-coated filters. Furthermore, adenoviral vectors containing the fulllength human HPSE-1 cDNA in sense orientation (Ad-S/hep) were constructed to investigate CREB effects on HPSE-1. Restoration of HPSE-1 expression and functionality following Ad-S/hep infection of KCREB-transfected 70W cells recovered melanoma cell invasiveness. These results demonstrate that KCREB inhibits HPSE-1 and suggest that one of the roles CREB plays in the acquisition of melanoma cells metastatic phenotype is affecting HPSE-1 activity. J. Cell. Biochem. 93: 215-223, 2004. (c) 2004 Wiley-Liss, Inc.
\end{abstract}

Key words: heparanase; malignant melanoma; CREB; dominant negative; invasion

Most of molecular events associated with melanoma growth, neovascularization, and

Abbreviations used: BCA, bicinchoninic acid; BSA, bovine serum albumin; CREB, cAMP response element-binding protein; DMEM, Dulbecco's modified Eagle's medium; ECM, extracellular matrix; ELISA, enzyme-linked immunosorbent assay; FBS, fetal bovine serum; GAPDH, glyceraldehyde-3-phosphate dehydrogenase; HPSE-1, heparanase; HRP, horse radish peroxidase; HS, heparan sulfate glycosaminoglycan chains; HSPG, heparan sulfate proteoglycans; IgG, immunoglobulin G; PAb, polyclonal antibody; PBS, phosphate-buffered saline; PDVF, polyvinylidene difluoride; PMSF, phenyl methyl sulfonyl fluoride; $\mathrm{P} / \mathrm{S}$, penicillin/streptomycin; TBS, tris-buffered saline.

Grant sponsor: NIH (to DM); Grant number: 5R0-1 CA86832; Grant sponsor: Louisiana Governor's Biotechnology Initiative.

*Correspondence to: Dr. Dario Marchetti, Department of Comparative Biomedical Sciences, Room 2522-SVM, Skip Bertman Drive, Louisiana State University-Baton Rouge, Baton Rouge, LA 70803.

E-mail: dmarchetti@vetmed.lsu.edu

Received 18 June 2004; Accepted 21 June 2004

DOI 10.1002/jcb.20231

(c) 2004 Wiley-Liss, Inc. metastasis are influenced by interactions between neoplastic cells and components of their extracellular matrix (ECM) [Herlyn and Shih, 1994; Kopf et al., 1995]. Heparan sulfate proteoglycans (HSPG), along with other proteoglycans and structural proteins, are key components of the cell surface and ECM [Bernfield et al., 1999; Sanderson, 2001]. The realization that cell-surface HSPG mediate extracellular information has raised questions about their selective degradation at the heparan sulfate glycosaminoglycan chains (HS) level.

Heparanase (HPSE-1) is an endo- $\beta$-D-glucuronidase that cleaves HS at specific intrachain sites, resulting in the formation of fragments (10-20 sugar units) [Nakajima et al., 1984, 1988; Vlodavsky and Friedmann, 2001] which are capable of binding potent angiogenic and paracrine growth factors [Vlodavsky and Friedmann, 2001]. Importantly, HPSE-1 is to be distinguished from other HS-degradative enzymes, such as heparitinases and heparinases from Flavobacterium heparinum, or endoglucosaminidases, which are eliminases that cleave HS into non-biologically active 
di- or tetra-saccharide units [Liu et al., 2002]. Increased levels of HPSE-1 activity are associated with several metastatic tumor types [Marchetti et al., 1996; Vlodavsky and Friedmann, 2001], including brain-metastatic melanoma [Marchetti et al., 1993, 1996, 2003; Marchetti and Nicolson, 2001], and HPSE-1 has been also implicated in tumor angiogenesis [Vlodavsky and Friedmann, 2001]. Because melanocyte proliferation and differentiation are positively regulated by agents that increase cAMP [Gonzalez and Montminy, 1989], we have focused on the transcription factor cAMP response element-binding protein (CREB) which is known to be activated by cAMP.

The $43 \mathrm{kDa}$ CREB protein binds the consensus motif 5'-TGACGTCA-3' and activates transcription. It was initially isolated from rat brain tissue [Gonzalez and Montminy, 1989] and found to be ubiquitously expressed belonging to the leucine zipper class of proteins [Borrelli et al., 1992]. The CREB protein is an important transcription factor which is activated by multiple signal transduction pathways in response to hormones, growth factors, cytokines, and stress [Gonzalez and Montminy, 1989]. CREB is also a mediator of tumor growth and metastasis of human melanoma [Yang et al., 1996; Xie et al., 1997; Jean et al., 1998; Jean and Bar-Eli, 2000]. CREB overexpression is found in melanoma progression from radial growth phase to vertical phase [Nyormoi and Bar-Eli, 2003]. Inhibiting CREB activity with a dominant negative CREB reduces melanoma metastatic potential [Xie et al., 1997]. CREB also regulates the expression of type IV collagenase (MMP-2) and the cell-surface adhesion molecule MUC18, both of which can contribute to the invasive phenotype of melanoma cells [Jean and Bar-Eli, 2000]. Additionally, CREB acts as a survival factor for melanoma by reducing susceptibility to apoptosis [Jean et al., 1998].

To study the contribution of CREB to HPSE-1 expression and activity as related to human melanoma metastasis, we have used a dominant-negative cDNA construct of CREB, KCREB that has been mutated in the DNAbinding domain [Walton et al., 1992; Xie et al., 1997]. When overexpressed, this protein suppresses transcription of factors capable of associating with CREB [Wada et al., 1991; Abdel-Hafiz et al., 1993].

In the present study, we have demonstrated: (1) a KCREB-mediated inhibition of cell inva- sion by highly aggressive and brain-metastatic human melanoma cells (70W); (2) a downregulation of HPSE-1 mRNA and activity (but not protein) in KCREB-transfected 70W cells; and (3) a restoration of cell invasiveness when KCREB-transfected $70 \mathrm{~W}$ cells were infected with an adenoviral vector expressing human HPSE-1 (Ad-S/hep). These results demonstrate for the first time that CREB regulates melanoma cell invasion by controlling HPSE-1 activity.

\section{MATERIALS AND METHODS}

\section{Materials}

Dulbecco's modified Eagle's medium (DMEM)/ F-12 nutrient medium and trypsin-EDTA were purchased from Gibco (Grand Island, New York, NY), and fetal bovine serum (FBS) from Hyclone Laboratories (Logan, UT). Transwell cell culture chambers were purchased from Corning Incorporated Life Sciences (Acton, MA), while Matrigel ${ }^{\mathrm{TM}}$ was obtained from BD Biosciences Discovery Labware (Bedford, MA). Lipofectin was purchased from Invitrogen, Inc. (Carlsbad, CA). Polyclonal antibodies to human HPSE-1 were kindly provided by Dr. Laurie A. Dempsey (Mayo Clinic, Rochester, MN). All other chemicals used were reagent-grade or better.

\section{Tissue Culture}

Human brain-metastatic melanoma $70 \mathrm{~W}$ cells were maintained as monolayer cultures in a $1: 1(\mathrm{v} / \mathrm{v})$ mixture of DMEM/F-12 supplemented with $10 \%(\mathrm{v} / \mathrm{v})$ FBS [Marchetti et al., 1996, 2003; Reiland et al., 2004]. Human 70W cells were chosen as because they are highly invasive and produce HPSE-1 at elevated levels versus parental MeWo [Marchetti et al., 1993, 1996]. Cells were maintained at $37^{\circ} \mathrm{C}$ in a humidified $5 \% \mathrm{CO}_{2}, 95 \%$ air (v/v) atmosphere and passaged using trypsin-EDTA before reaching confluency. The transformed embryonic kidney cell line 293 was grown in DMEM/F-12, supplemented with $10 \%$ FBS, penicillin (100 U/ $\mathrm{ml})$, and streptomycin $(100 \mu \mathrm{g} / \mathrm{ml})$. The 293 cells were used for the production of adenoviral vectors [Uno et al., 2001].

\section{Dominant Negative CREB (KCREB)}

The production of the dominant-negative KCREB (pRSV-KCREB) plasmid and subsequent luciferase assays were performed as 
previously described [Wada et al., 1991; Walton et al., 1992; Yang et al., 1996].

\section{Recombinant Adenovirus Containing Human HPSE-1}

An adenoviral expression vector kit (Takara Biomedicals, Inc., Tokyo, Japan) was used to generate recombinant adenovirus for the expression of human HPSE-1 [Uno et al., 2001]. Replication-deficient E1- and E3-deleted recombinant adenovirus serotype 5 (Ad5) was used as the viral backbone. Plasmid DNA containing the cloned HPSE-1 and the synthetic oligonucleotides Hep-5' (complementary to the $5^{\prime}$ end of the gene) and Hep-3' (complementary to the $3^{\prime}$ end of the gene) were used to create PCR products encompassing the HPSE-1 sequence (1,632 bp). PCR products were treated with T4 DNA polymerase to generate uniformed blunt ends required for the elongation reaction into a pAxCAwt cosmid provided by the Takara kit. After cloning HPSE-1 into the cosmid vector, availability of recombinant cosmids containing the target gene in sense $\left(5^{\prime}-3^{\prime}\right.$ orientation under the CAG promoter of the vector) orientation was confirmed by restriction analysis. Cosmid DNAs were produced in large quantities and after gradient purification were used for cotransfection with the adenovirus genomic DNA-terminal protein complex (DNA-TPC provided by the kit) into the 293 cells. Following the protocol, recombinant adenoviruses expressing human HPSE-1 in sense orientation (Ad-S/hep) were generated. Integrity of recombinant viruses was confirmed using PCR and restriction analysis. The E1- and E3-deleted replication deficient adenovirus pAd5-Blue was used as control vector. Viral titer was quantified by determination of the $50 \%$ infectivity on tissue culture 293 cells (TCID 50).

\section{KCREB Transfection and Adenoviral Infection}

$70 \mathrm{~W}$ cells were plated in 6 -well $\left(10^{6}\right.$ cells/well $)$ tissue culture dishes (Corning, Inc., New York). Twenty-four hours later, they were washed twice in serum-free DMEM/F-12. Cells were then transfected with KCREB or mock transfected using lipofectin $(10 \mu \mathrm{g} / \mathrm{ml})$ following a commercially available protocol (Invitrogen, Inc.). After $24 \mathrm{hr}$, cells were washed twice with phosphate-buffered saline (PBS) containing $2 \mathrm{mM}$ EDTA, and then infected with the adenovirus vectors (Ad-S/hep or pAd5-Blue) diluted in serum-free DMEM/F12. Cells were infected with vectors at a multiplicity of infection (MOI) of 50. Plates were incubated for $1 \mathrm{~h}$, rocking every $10 \mathrm{~min}$. Infection was stopped by adding DMEM/F12 containing 10\% FBS, penicillin $(100 \mathrm{U} / \mathrm{ml})$, and streptomycin $(100 \mu \mathrm{g} / \mathrm{ml})$. Cells were then incubated for additional $24 \mathrm{~h}$ at $37^{\circ} \mathrm{C}$ in a humidified $5 \% \mathrm{CO}_{2}, 95 \%$ air $(\mathrm{v} / \mathrm{v})$ atmosphere before experiments were performed.

\section{Isolation of RNA, HPSE-1 Primers, and RT-PCR}

Total RNA was isolated from cells using RNeasy kit (Qiagen, Inc., Valencia, CA). Reverse transcription was performed using oligodT primers as per manufacturer's instructions (Promega, Madison, WI) and PCR was performed for 35 cycles of denaturation at $94^{\circ} \mathrm{C}$ for $30 \mathrm{~s}$, annealing at $56^{\circ} \mathrm{C}$ for $30 \mathrm{~s}$, and at $72^{\circ} \mathrm{C}$ for 1 min using a thermal cycler (ABI 9600, Applied Biosystems, Foster City, CA). The following specific primers were used: HPSE-1 sense (HPSE-S: 5'-GTT GCT CCT GGA CTA CTG CTC TT- $3^{\prime}$ ), and antisense (HPSE-AS: $5^{\prime}$-AGC CAC ATA AAG CCA GCT GC-3'); control glyceraldehyde-3-phosphate dehydrogenase (GAPDH), sense (5'-AGC CAC ATC GCT CAG AAC AC- $3^{\prime}$ ), and antisense (5'-GAG GCA TTG CTG ATG ATC TTG-3'). PCR products were subsequently resolved on a $1.5 \%$ agarose gel and visualized by ethidium bromide staining using a Versadoc imaging system (Bio-Rad Laboratories, Hercules, CA).

\section{Western Blotting Analysis}

Cells to be analyzed for CREB protein expression were plated in 6-well dishes and incubated at $37^{\circ} \mathrm{C}$ for $24 \mathrm{~h}$. Cells were then transfected with KCREB plasmid. Forty-eight hours later, they were scraped off the dish in cold $\left(4^{\circ} \mathrm{C}\right)$ PBS and nuclear extract was separated from total cell extract [Xie et al., 1997]. For studies involving HPSE-1, cells were subsequently infected with Ad-S/hep (or pAd5-Blue control) and incubated for an additional $24 \mathrm{~h}$ after transfection with KCREB. They were then released using trypsin, centrifuged at $300 \mathrm{rpm}$ for $5 \mathrm{~min}$, and resuspended in lysis buffer [trisbuffered saline, TBS ( $\mathrm{pH}$ 7.4) containing TritonX $100(0.5 \%)$, leupeptin $(10 \mu \mathrm{g} / \mathrm{ml})$, pepstatin $(10 \mu \mathrm{g} / \mathrm{ml})$, and phenyl methyl sulfonyl fluoride (PMSF) $(0.2 \mathrm{mM})]$. Cells were vortexed and lysed on ice for $10 \mathrm{~min}$. They were then centrifuged for $10 \mathrm{~min}$ at $13,000 \mathrm{rpm}$ at $4^{\circ} \mathrm{C}$, and the supernatant was collected. For KCREB and 
HPSE-1 detection, protein concentration was determined using a bicinchoninic acid (BCA) assay (Pierce, Rockford, IL). Because HPSE-1 is a low-abundance protein, $40-60 \mu \mathrm{g}$ of total celllysate had to be electrophoresed in order to detect adequate HPSE-1 levels. Protein samples $(40-60 \mu \mathrm{g})$ were heated to $100^{\circ} \mathrm{C}$ for $5 \mathrm{~min}$ with Laemmli sample buffer [Laemmli, 1970] and separated on a $10 \%$ Criterion gel (Tris- $\mathrm{HCl}$, Bio-Rad Laboratories). The gel was transferred to a polyvinylidene difluoride (PDVF) membrane (Pierce Endogen, Inc., Rockford, IL) and incubated for $1 \mathrm{~h}$ in a blocking reagent $[3 \%(\mathrm{w} / \mathrm{v})$ non-fat dry milk, $0.5 \%(\mathrm{w} / \mathrm{v})$ bovine serum albumin (BSA), $0.3 \%$ (v/v) Tween-20 on PBS, $\mathrm{pH}$ 7.5]. CREB was labeled using an anti-CREB antibody which recognizes both CREB and KCREB (1:500 dilution) (Santa Cruz Biotechnology, Inc., Santa Cruz, CA) while HPSE-1 was labeled using anti-HPSE-1 polyclonal antibody (PAb) (1:5,000). Membranes were incubated with either antibody in $3 \%(\mathrm{w} / \mathrm{v})$ non-fat dry milk and $0.5 \%(\mathrm{w} / \mathrm{v}) \mathrm{BSA}$ for $18 \mathrm{~h}$. They were then washed with 0.5\% IGE-PAL (CA-630, Sigma Chemical Company, St. Louis, MO) in Tris-buffer (20 mM Tris, $150 \mathrm{mM} \mathrm{NaCl}, \mathrm{pH}$ 7.4) for $1 \mathrm{~h}$, changing the solution six to eight times. PDVF membranes were then incubated with secondary antibodies in $3 \%(\mathrm{w} / \mathrm{v})$ non-fat dry milk and $0.5 \%$ (w/v) BSA for 30 min. Goat antimouse-horse radish peroxidase (HRP) antibody was used for CREB (1:10,000 dilution; Bio-Rad Technologies, Inc., Hercules, CA), and bovine anti-rabbit-HRP antibody was used for HPSE-1 detection (1:5,000 dilution; Santa Cruz Biotechnology, Hercules, CA). Membranes were washed and developed using the Super-signal west femto maximum sensitivity substrate (Pierce Endogen, Inc.). Labeling was detected using the Versadoc imaging system (Bio-Rad).

\section{Chemoinvasion Assays}

Cell invasion (72 h) was assayed using Transwell cell culture chambers $(8 \mu \mathrm{m}$ pore size, $6.5 \mathrm{~mm}$ diameter) coated with artificial basement membrane or Matrigel ${ }^{\mathrm{TM}}$ (diluted 1:30 with cold DMEM/F-12, $100 \mu \mathrm{l}$ final coating volume) as previously described [Reiland et al., 2004].

\section{HPSE-1 Activity Assays}

A commercial HS degrading enzyme assay kit (Takara Mirus Biomedical, Inc., Madison, WI) was used to determine HPSE-1 activity in the presence or absence of KCREB. Cells equivalents $\left(2.5 \times 10^{6} /\right.$ well $)$ were incubated with a biotinylated-HS (b-HS) and detected by an enzyme-linked immunosorbent assay (ELISA)type assay according to the manufacturer's instructions. Activity was determined by comparison to known HPSE-1 activity values obtained from standards supplied by the kit [Reiland et al., 2004].

\section{RESULTS}

\section{KCREB Inhibits 70W Cell Invasion Through Matrigel-Coated Filters}

Brain-metastatic $70 \mathrm{~W}$ cells were compared before and after transfection with KCREB mutant gene to assess the role of CREB in cell penetration through the basement membrane, an important barrier which must be breached for tumor cells to invade and metastasize [Liotta et al., 1991; Wada et al., 1991; Bogenrieder and Herlyn, 2003]. First, CREB expression was confirmed at the protein level by performing Western blotting analyses using an antibody which recognized both CREB and KCREB (Fig. 1A). Second, we performed chemoinvasion assays using an artificial basement membrane $\left(\right.$ Matrigel $\left.^{\mathrm{TM}}\right)$. Cells (70W) exhibited high capabilities to penetrate through Matrigel-coated filters [Marchetti et al., 1993, 1996; Fig. 1B]. Conversely, KCREB-transfected 70W cells displayed a significantly decreased (4.5-fold; $P<0.001)$ ability to invade through these filters (Fig. 1B). These studies show that expression of KCREB by melanoma cells decreased their capacity to penetrate though the basement membrane.

\section{KCREB-Transfected 70W Cells Show Decreased HPSE-1 Transcript Expression}

The metastatic potential of tumor cells depends on proper vascularization of the tumor and its ability to degrade HSPG. Downregulation or deactivation of HPSE-1 may account for the decrease in invasiveness of KCREB-transfected $70 \mathrm{~W}$ cells. To examine the significance of KCREB in affecting human HPSE-1 in brainmetastatic melanoma, we transfected $70 \mathrm{~W}$ cells with a KCREB-containing vector and investigated its effects on HPSE-1 transcript expression. A specific HPSE-1 transcript (470 bp) amplification was detected by semiquantitative RT-PCR which was significantly downregulated in KCREB-transfected cells (Fig. 2). 


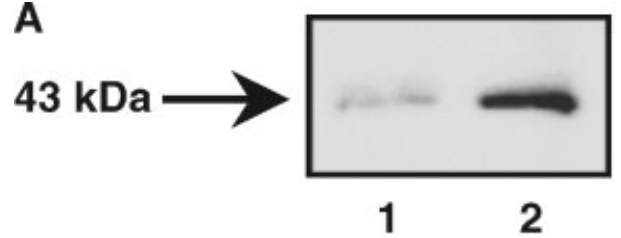

B

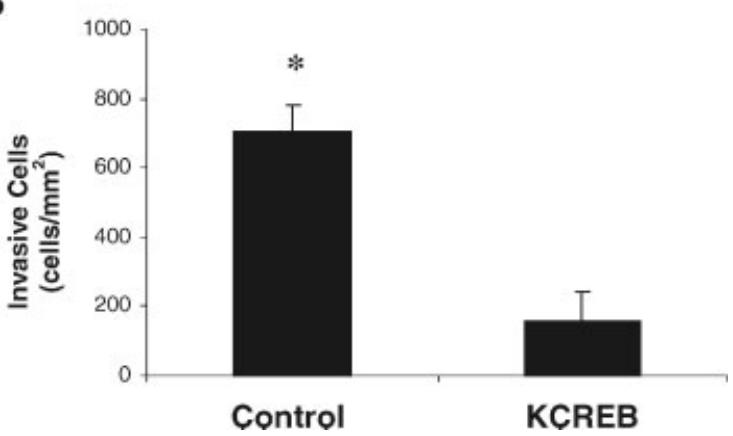

Fig. 1. Cells (70W) transfected with dominant-negative CREB (KCREB) mutant show increased cAMP response elementbinding protein (CREB) protein expression by Western blotting but a decreased invasion. A: Western blotting analysis using an anti-CREB antibody, which recognizes both CREB and KCREB. Nuclear extract was taken from cells transfected with KCREB. Cells transfected with KCREB (lane 2) display an increase in the $43 \mathrm{kDa}$ band, showing successful transfection of the KCREB plasmid. B: Brain-metastatic 70W cells were transfected with dominant negative KCREB and placed onto invasion chambers $\left(8 \mu \mathrm{m}\right.$ pores) for $72 \mathrm{~h}$ at $37^{\circ} \mathrm{C}$. Cells that invaded through an artificial basement membrane (Matrige ${ }^{\mathrm{TM}}$ ) were stained with the Diff-Quick staining kit, photographed, and counted (see "Materials and Methods"). KCREB-transfected 70W cells (lane 2) show a significant decrease in invasion versus mock control (lane 1). Bars represent the mean \pm SD of triplicate determinations $\left({ }^{*} P<0.001\right)$. Student's $t$-test was used as statistical method.

\section{Decrease of HPSE-1 Activity in KCREB-Transfected Cells}

As a subsequent step in our investigations, we analyzed HPSE-1 activity in KCREB-transfected $70 \mathrm{~W}$ cells. Cell lysates from these cells were analyzed for HPSE-1 activity as we have

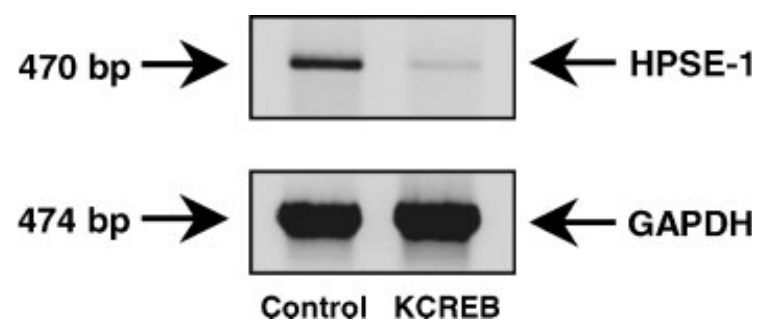

Fig. 2. Dominant-negative KCREB inhibits heparanase (HPSE1) mRNA expression. RT-PCR analysis for HPSE-1 transcript expression in 70W cells transfected with KCREB using lipofectin (lane 2) or incubated with lipofectin alone as control (lane 1). previously described [Reiland et al., 2004]. A $36 \%$ decrease in HPSE-1 activity in KCREBtransfected $70 \mathrm{~W}$ cells was observed compared to control 70W (Fig. 3). Furthermore, an inhibition of HPSE-1 activity in KCREB-transfected 70W cells correlated with the observed decrease in HPSE-1 mRNA transcript in KCREBtransfected 70W cells (Fig. 2).

\section{HPSE-1 Modulation by Ad-S/hep Infection of KCREB-Transfected 70W Cells}

To examine the effects of Ad-S/hep infection on HPSE-1 mRNA and protein levels in KCREB-transfected 70W cells, we performed RT-PCR and Western blotting analyses. Cells (70W) were transfected with KCREB or mock controls. Cells, previously KCREB-transfected, and subsequently infected with Ad-S/hep showed an increase in HPSE-1 transcript (Fig. 4A, lanes 2 and 4). HPSE-1 is a heterodimer consisting of a $50 \mathrm{kDa}$ and a $8 \mathrm{kDa}$ band processed from a pro-enzyme precursor $(65 \mathrm{kDa})$ by proteolytic cleavage. Presence of the $8 \mathrm{kDa}$ band is essential for its enzymatic activity [Fairbanks et al., 1999; McKenzie et al., 2003]. Consistent with these findings, we detected a $58 \mathrm{kDa}$ as active heterodimer produced in our cells (Fig. 4B). We found a $23 \%$ increase in HPSE-1 protein level when KCREBtransfected 70W cells were infected with the Ad$\mathrm{S} /$ hep. However, and of note, HPSE-1 protein levels remained unchanged among the various treatments (Fig. 4B).

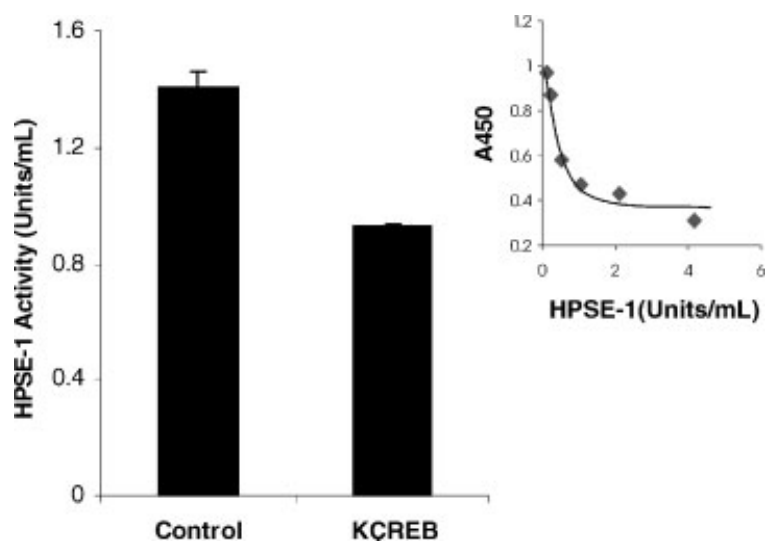

Fig. 3. KCREB inhibits HPSE-1 activity. HPSE-1 activity assays in cell lysates of $70 \mathrm{~W}$ cells transfected with KCREB or mock control. HPSE-1 activity was determined by comparison with known standards (see "Materials and Methods"). 
A

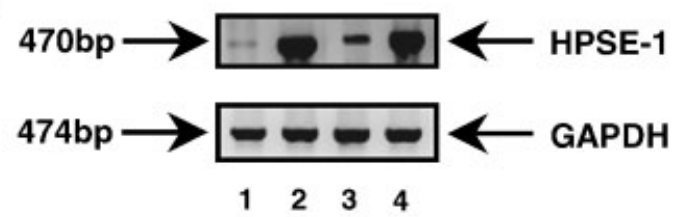

B

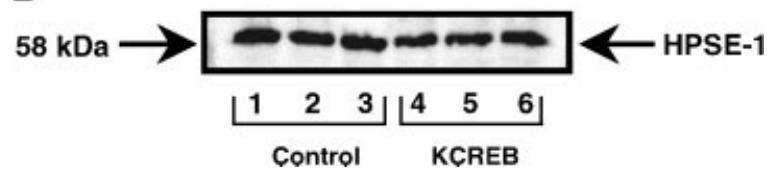

Fig. 4. RT-PCR and Western blotting analysis of KCREBtransfected 70W infected with Ad-S/hep. A: Cells (70W) were transfected with KCREB (lanes $\mathbf{3}$ and $\mathbf{4}$ ) or incubated with lipofectin alone (lanes $\mathbf{1}$ and 2). They were then subsequently infected with Ad-S/hep (lanes 2 and 4 ) or control pAd5-Blue (lanes 1 and 3). Cells infected with Ad-S/hep showed an increase in HPSE-1 transcript. B: Western blotting analysis for HPSE-1. Cells (70W) were transfected with KCREB and analyzed for HPSE-1 content. Equal amounts $(40-60 \mu \mathrm{g})$ of protein were loaded on gels and HPSE-1 protein levels were detected using a rabbit polyclonal antibody and horse radish peroxidase (HRP)-anti-rabbit immunoglobulin G (IgG) followed by using the Super-signal west femto maximum sensitivity substrate (see "Materials and Methods"). Bands were visualized on a Versadoc imaging system. Panel 1: Mock control. Panel 2: KCREB-transfected 70W cells. Lanes 1 and 4: No treatment; (lanes 2 and 5) 70W transfected with pAd-5Blue; (lanes 3 and 6) 70W transfected with Ad-S/hep.

\section{Infection of KCREB-Transfected 70W Cells With Ad-S/hep Restores Invasive Capabilities}

To investigate whether HPSE-1 directly correlated with a loss in CREB functionality,
KREB-transfected 70W cells were subsequently infected with either Ad-S/hep or pAd5-Blue control. These cells then were then plated onto Matrigel-coated filters and chemoinvasion assays performed. Cells showed decreased invasiveness when expressing the KCREB protein, however, HPSE-1 activity was restored following Ad-S/hep as well as cell ability to invade (Fig. 5).

\section{DISCUSSION}

In this report, we demonstrate for the first time that (1) CREB is involved in HPSE-1mediated invasive mechanisms, and (2) dominant negative CREB (KCREB) inhibits HPSE-1 functionality in brain-metastatic melanoma cells $(70 \mathrm{~W})$. We showed that expression of dominant-negative KCREB in 70W cells markedly reduces HPSE-1 mRNA and activity (Figs. 1 and 4). Our results also demonstrate that KCREB regulates HPSE-1 transcription (Fig. 2) but not HPSE-1 protein expression (Fig. 4B) and furthermore that the infection of KCREB-transfected 70W cells with Ad-S/hep restores their invasive capabilities (Fig. 5).

The molecular basis of human malignant melanoma progression has remained largely unknown despite the fact that the worldwide incidence of melanoma is increasing more than that of any other neoplastic disease [Herlyn and Shih, 1994; Kopf et al., 1995]. Invasion and
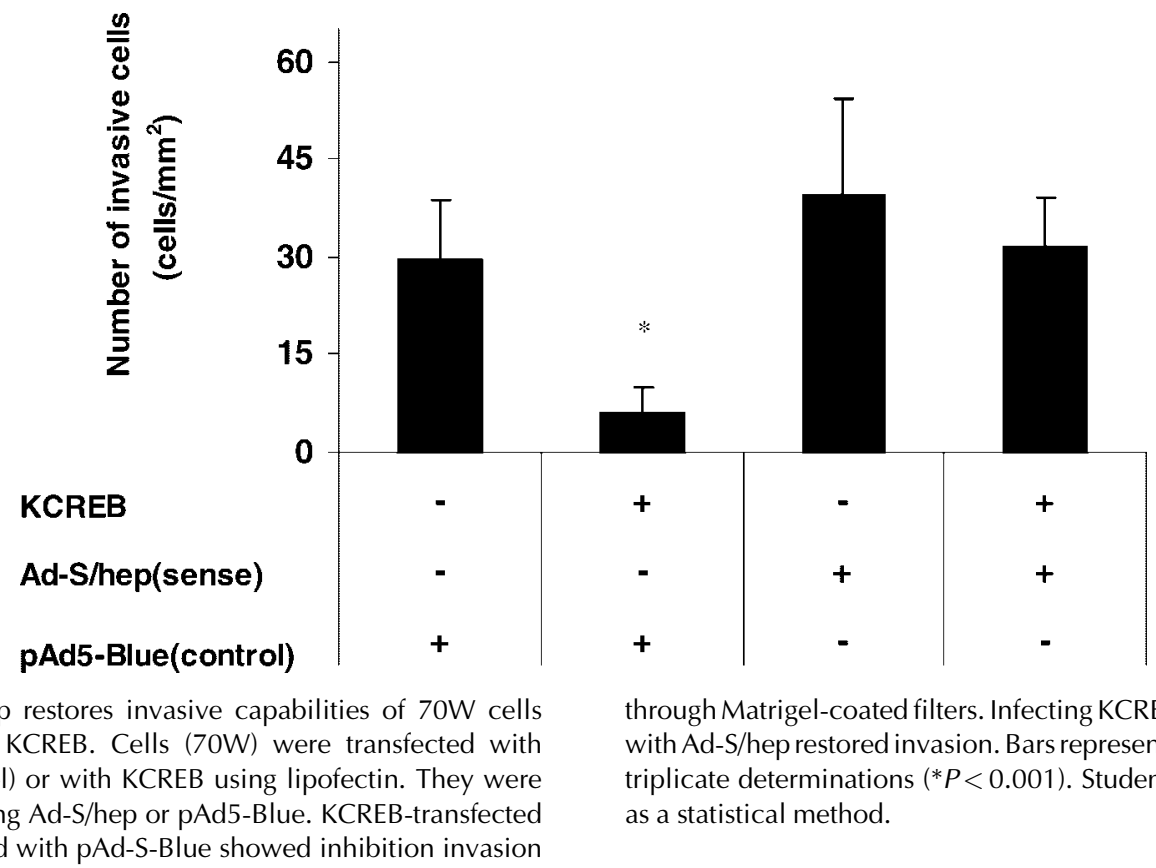

Fig. 5. Ad-S/hep restores invasive capabilities of $70 \mathrm{~W}$ cells transfected with KCREB. Cells (70W) were transfected with lipofectin (control) or with KCREB using lipofectin. They were then infected using Ad-S/hep or pAd5-Blue. KCREB-transfected $70 \mathrm{~W}$ and infected with pAd-S-Blue showed inhibition invasion

through Matrigel-coated filters. Infecting KCREB transfected cells with $\mathrm{Ad}-\mathrm{S} /$ hep restored invasion. Bars represent the mean $\pm \mathrm{SD}$ of triplicate determinations $\left({ }^{*} P<0.001\right)$. Student's $t$-test was used as a statistical method. 
metastasis are characteristic features of malignant tumors like melanoma, and are among the greatest impediments to curing cancer [Liotta et al., 1991; Bogenrieder and Herlyn, 2003]. Their invasive potential depends, among many factors, on their ability to degrade HSPG. Indeed, HPSE-1 activation provides a mechanism to explain the increased metastatic potential of human melanoma cells [Marchetti et al., 1993].

The dominant-negative construct KCREB used in this study displays an altered CREB DNA-binding activity due to a single base pair change from arginine to leucine at position 287. This arginine is conserved within the basic region of the leucine zipper DNA-binding motif in more than 30 different members of the AP1/ ATF family of transcription factors [Ellenberger et al., 1992]. The KCREB protein yields proper heterodimerization with AP1/CRE-binding factors, however, due to its poor affinity to DNA, CREB-associated proteins confer an altered transcriptional activity. As a result, expression of the dominant negative CREB will quench any of the known CREB-associated proteins including members of the ATF [Wada et al., 1991; Abdel-Hafiz et al., 1993], AP1 families [Hai and Curran, 1991], and the $265 \mathrm{kDa}$ CREB-binding protein (CBP) that links CREB to the basal transcription machinery through its association with TFIIB [Kwok et al., 1994]. In the KCREB clone used in the present study, endogenous CREB may still interact with CRE target sequences, yet, due to the quenching properties of KCREB, endogenous CREB is likely to associate with different transcription factors. Such a change would result in different size complexes and modified transcriptional activities.

One mechanism of CREB transcriptional activation is its phosphorylation of Ser-133 by the catalytic subunit of cAMP-activated protein kinase A [Gonzalez and Montminy, 1989]. Many other Ser/Thr kinases can phosphorylate CREB including protein kinase C [Borrelli et al., 1992]. It is interesting to note that regulation of HPSE1 expression and secretion by protein kinase $\mathrm{A}$ and protein kinase $\mathrm{C}$ has been recently reported [Navarro et al., 2004]. Of note, CREB may not directly regulate HPSE-1 since CRE sites have not been detected in HPSE-1 promoter [Jiang et al., 2002].

Down-regulation of HPSE-1 activity might be one of the mechanisms that account for the decrease in invasiveness of the KCREBtransfected cells (Fig. 1B). Recent findings from other laboratories imply that in addition to contributing to HSPG degradation, HPSE-1 also mediate adhesion of neoplastic cells to the ECM [Goldshmidt et al., 2003]. As such, HPSE1 may modulate adhesion and facilitate cell migration and invasion.

Heparanase is regulated at multiple levels including during transcription, translation [Shteper et al., 2003; Chen et al., 2004], posttranslational events due to glycosylation or protein cleavage [Fairbanks et al., 1999; McKenzie et al., 2003; Simizu et al., 2004], and sub-cellular localization [Sasaki et al., 2004]. These multiple layers of regulation can result in HPSE-1 message, protein, or whole cell enzymatic activity levels which may not directly correlate with heparanase-mediated biological activity. As an example, HPSE-1 is made as a $65 \mathrm{kDa}$ pro-enzyme which needs to be cleaved for enzymatic activity [Fairbanks et al., 1999; McKenzie et al., 2003]. Of relevance, increases in HPSE-1 activity without corresponding increases in its protein levels have recently been reported and are consistent with our results [He et al., 2004]. This may reflect changes in HPSE-1 localization that can alter its activity levels in cells. It has been reported that changes in HPSE-1 localization, i.e., to the cell surface, can lead to increases in heparanase-mediated function [Sasaki et al., 2004].

CREB is known to regulate a cassette of genes. Therefore, and as determined in our experiments, CREB may regulate HPSE-1 at multiple levels. This was unexpected but may be due to the above-mentioned extensive HPSE-1 regulatory patterns.

In summary, our data demonstrate that the transcription factor CREB is involved in regulating HPSE-1 gene transcription, activity and functionality. Since HPSE-1 is involved in the progression of malignant melanoma, these results suggest that $\mathrm{CREB}$ and possibly its associated proteins may play important roles in the acquisition of the brain-metastatic phenotype of human melanoma cells.

The therapeutic modalities to control tumor growth and metastasis of human melanoma are very limited. Based on our studies that CREB serves as HPSE-1 modulator, it is conceivable to use CRE-based oligonucleotides as a decoy transcription factors to inhibit HPSE-1 and melanoma metastasis. This possibility is currently being investigated in our laboratory. 


\section{ACKNOWLEDGMENTS}

We express our gratitude to Dr. Richard Goodman (Oregon Health Sciences, Portland, OR) for providing pRS-KCREB. We thank Dr. Choulijenko and Dr. Kousoulas (SVM at LSU-Baton Rouge) for their help in generating Ad-S/hep vector. We also thank Jerry Travers, Jason and Bryan Blust for editorial assistance.

\section{REFERENCES}

Abdel-Hafiz HA, Chen CY, Marcell T, Kroll DJ, Hoeffler JP. 1993. Structural determinants outside of the leucine zipper influence the interactions of CREB and ATF-2: Interaction of CREB with ATF-2 blocks E1a-ATF-2 complex formation. Oncogene 8:1161-1174.

Bernfield M, Gotte M, Park PW, Reizes O, Fitzgerald ML, Lincecum J, Zako M. 1999. Functions of cell surface heparan sulfate proteoglycans. Annu Rev Biochem 68: 729-777.

Bogenrieder T, Herlyn M. 2003. Axis of evil: Molecular mechanisms of cancer metastasis. Oncogene 22:65246536.

Borrelli E, Montmayeur JP, Foulkes NS, Sassone-Corsi P. 1992. Signal transduction and gene control: The cAMP pathway. Crit Rev Oncog 3:321-338.

Chen G, Wang D, Vikramadithyan R, Yagyu H, Saxena U, Pillarisetti S, Goldberg IJ. 2004. Inflammatory cytokines and fatty acids regulate endothelial cell heparanase expression. Biochemistry 43:4971-4977.

Ellenberger TE, Brandl CJ, Struhl K, Harrison SC. 1992. The GCN4 basic region leucine zipper binds DNA as a dimer of uninterrupted alpha helices: Crystal structure of the protein-DNA complex. Cell 71:1223-1237.

Fairbanks MB, Mildner AM, Leone JW, Cavey GS, Mathews WR, Drong RF, Slightom JL, Bienkowski MJ, Smith CW, Bannow CA, Heinrikson RL. 1999. Processing of the human heparanase precursor and evidence that the active enzyme is a heterodimer. J Biol Chem 274: 29587-29590.

Goldshmidt O, Zcharia E, Cohen M, Aingorn H, Cohen I, Nadav L, Katz BZ, Geiger B, Vlodavsky I. 2003. Heparanase mediates cell adhesion independent of its enzymatic activity. FASEB J 17:1015-1025.

Gonzalez GA, Montminy MR. 1989. Cyclic AMP stimulates somatostatin gene transcription by phosphorylation of CREB at serine 133. Cell 59:675-680.

Hai T, Curran T. 1991. Cross-family dimerization of transcription factors Fos/Jun and ATF/CREB alters DNA binding specificity. Proc Natl Acad Sci USA 88:37203724.

He X, Brenchley PE, Jayson GC, Hampson L, Davies J, Hampson IN. 2004. Hypoxia increases heparanasedependent tumor cell invasion, which can be inhibited by antiheparanase antibodies. Cancer Res 64:39283933.

Herlyn M, Shih IM. 1994. Interactions of melanocytes and melanoma cells with the microenvironment. Pigment Cell Res 7:81-88.

Jean D, Bar-Eli M. 2000. Regulation of tumor growth and metastasis of human melanoma by the CREB transcription factor family. Mol Cell Biochem 212:19-28.
Jean D, Harbison M, McConkey DJ, Ronai Z, Bar-Eli M. 1998. CREB and its associated proteins act as survival factors for human melanoma cells. J Biol Chem 273: 24884-24890.

Jiang P, Kumar A, Parrillo JE, Dempsey LA, Platt JL, Prinz RA, Xu X. 2002. Cloning and characterization of the human heparanase-1 (HPR1) gene promoter. J Biol Chem 277:8989-8998.

Kopf AW, Salopek TG, Slade J, Marghoob AA, Bart RS. 1995. Techniques of cutaneous examination for the detection of skin cancer. Cancer 75:684-690.

Kwok RP, Lundblad JR, Chrivia JC, Richards JP, Bachinger HP, Brennan RG, Roberts SG, Green MR, Goodman RH. 1994. Nuclear protein CBP is a coactivator for the transcription factor CREB. Nature 370:223-226.

Laemmli UK. 1970. Cleavage of structural proteins during the assembly of the head of bacteriophage T4. Nature 227:680-685.

Liotta LA, Steeg PS, Stetler-Stevenson WG. 1991. Cancer metastasis and angiogenesis: An imbalance of positive and negative regulation. Cell 64:327-336.

Liu D, Shriver Z, Venkataraman G, El Shabrawi Y, Sasisekharan R. 2002. Tumor cell surface heparan sulfate as cryptic promoters or inhibitors of tumor growth and metastasis. Proc Natl Acad Sci USA 99:568-573.

Marchetti D, Nicolson GL. 2001. Human heparanase: A molecular determinant of brain metastasis. Adv Enzyme Reg 41:343-359.

Marchetti D, Menter D, Jin L, Nakajima M, Nicolson GL. 1993. Nerve growth factor effects on human and mouse melanoma cell invasion and heparanase production. Int J Cancer 55:692-699.

Marchetti D, McQuillan DJ, Spohn WC, Carson DD, Nicolson GL. 1996. Neurotrophin stimulation of human melanoma cell invasion: Selected enhancement of heparanase activity and heparanase degradation of specific heparan sulfate subpopulations. Cancer Res 56:2856-2863.

Marchetti D, Reiland J, Erwin B, Roy M. 2003. Inhibition of heparanase activity and heparanase-induced angiogenesis by suramin analogues. Int $\mathrm{J}$ Cancer 104:167-174.

McKenzie E, Young K, Hircock M, Bennett J, Bhaman M, Felix R, Turner P, Stamps A, McMillan D, Saville G, Ng S, Mason S, Snell D, Schofield D, Gong H, Townsend R, Gallagher J, Page M, Parekh R, Stubberfield C. 2003. Biochemical characterization of the active heterodimer form of human heparanase (Hpa1) protein expressed in insect cells. Biochem J 373:423-435.

Nakajima M, Irimura T, Di Ferrante N, Nicolson GL. 1984. Metastatic melanoma cell heparanase. Characterization of heparan sulfate degradation fragments produced by B16 melanoma endoglucuronidase. J Biol Chem 259: 2283-2290.

Nakajima M, Irimura T, Nicolson GL. 1988. Heparanases and tumor metastasis. J Cell Biochem 36:157-167.

Navarro E, Yegorov A, Schmitges F, Hadari Y, Bohlen P, Kussie P, Miao HQ. 2004. Regulation of heparanase expression and secretion by protein kinase $\mathrm{A}$ and protein kinase C. A.A.C.R Meeting Proceedings, Poster \#1809.

Nyormoi O, Bar-Eli M. 2003. Transcriptional regulation of metastasis-related genes in human melanoma. Clin Exp Metastasis 20:251-263.

Reiland J, Sanderson RD, Waguespack M, Barker SA, Long R, Carson DD, Marchetti D. 2004. Heparanase degrades syndecan-1 and perlecan heparan sulfate: Functional 
implications for tumor cell invasion. J Biol Chem 279: 8047-8055.

Sanderson RD. 2001. Heparan sulfate proteoglycans in invasion and metastasis. Semin Cell Dev Biol 12:89-98.

Sasaki N, Higashi N, Taka T, Nakajima M, Irimura T. 2004. Cell surface localization of heparanase on macrophages regulates degradation of extracellular matrix heparan sulfate. J Immunol 172:3830-3835.

Shteper PJ, Zcharia E, Ashhab Y, Peretz T, Vlodavsky I, Ben Yehuda D. 2003. Role of promoter methylation in regulation of the mammalian heparanase gene. Oncogene 22:7737-7749.

Simizu S, Ishida K, Wierzba MK, Osada H. 2004. Secretion of heparanase protein is regulated by glycosylation in human tumor cell lines. J Biol Chem 279:2697-2703.

Uno F, Fujiwara T, Takata Y, Ohtani S, Katsuda K, Takaoka M, Ohkawa T, Naomoto Y, Nakajima M, Tanaka N. 2001. Antisense-mediated suppression of human heparanase gene expression inhibits pleural dissemination of human cancer cells. Cancer Res 61:7855-7860.
Vlodavsky I, Friedmann Y. 2001. Molecular properties and involvement of heparanase in cancer metastasis and angiogenesis. J Clin Invest 108:341-347.

Wada T, Watanabe H, Usuda Y, Handa H. 1991. Different biological activities of the hetero- and homodimers formed by the 47- and 43-kilodaltons proteins of transcription factor ATF/E4TF3. J Virol 65:557-564.

Walton KM, Rehfuss RP, Chrivia JC, Lochner JE, Goodman RH. 1992. A dominant repressor of cyclic adenosine $3^{\prime}, 5^{\prime}$-monophosphate (cAMP)-regulated enhancer-binding protein activity inhibits the cAMP-mediated induction of the somatostatin promoter in vivo. Mol Endocrinol 6:647-655

Xie S, Price JE, Luca M, Jean D, Ronai Z, Bar-Eli M. 1997. Dominant-negative CREB inhibits tumor growth and metastasis of human melanoma cells. Oncogene 15: 2069-2075.

Yang YM, Dolan LR, Ronai Z. 1996. Expression of dominant negative CREB reduces resistance to radiation of human melanoma cells. Oncogene 12:2223-2233. 